\title{
104
}

\section{Realizing a vision?}

Clare Tagg

Open University Business

School

Milton Keynes

United Kingdom
Bill Tagg

Tagg Oram Partnership

59 Carlisle Avenue, St Albans

Hertfordshire

United Kingdom

\section{Ian Oram}

The Open University

Milton Keynes

United Kingdom

\begin{abstract}
The way in which Information Technology (IT) has been viewed and used for over eleven years in a United Kingdom (UK) state primary school is told by the participants. This story reveals that the vision which lay behind the initial (funded) IT project has not been sustained. The reasons behind this loss of vision are analyzed both in terms of internal and external influences.
\end{abstract}

Main conference themes: visions

Educational areas: primary education

Study topics:

Secondary keywords: attitudes, case studies, innovation, logo, problem solving 


\section{INTRODUCTION}

Academic educationalists or government ministers may have their views about how Information Technology (IT) should be used in schools, but what actually happens depends on the teachers, the children and the local support. This paper traces how the attitudes and use of IT in a state primary school (JMI) have changed over the last eleven years. The story is told through the words of the Regional Director who was heavily involved in the school's first IT project, the head teacher who provided much of the early impetus, a teacher who worked with her on Logo (Logo Teacher), a teacher who has taught at the school throughout the period (Teacher), the current IT coordinator who has been at the school since 1986 and a parent helper who has provided some technical support for the last 4 years and has taught children Logo using the original computer network for half day a week for the last two years.

\section{CONTEXT}

The story begins in 1982 with the United Kingdom (UK) Government's Microelectronics Education Programme (MEP). "MEP was about promoting what we were already sure of and researching areas of the curriculum where it was felt IT had potential. Funds were allocated on a regional basis. Regions had to seek permission to spend funds allocated to them and one of the proposals which was eventually approved was the Logo Project" (Regional Director). "There were teachers involved from five schools. They had no computing experience and the schools were chosen so that there was a mix of sociological backgrounds. Each school was equipped with an Apple II computer, printer and Edinburgh turtle" (Head Teacher). Although JMI was not one of the schools in the original project the new head appointed in 1983 brought the project with her (including the hardware).

She found "a school set with its own traditions. The deputy head had been there for 25 years and three other teachers had 39 years of service between them. There was one $480 \mathrm{Z}$ [an 8 bit CP/M machine] plus cassette recorder, unused."(Head Teacher) JMI is a one form entry voluntary aided village church school in Southern England.

\section{The vision}

The Regional Director had a clear vision for the aims of the Logo project: "Today, it is well known that IT, used appropriately, can have a profound effect on the way we think as well as what we learn about. In the early eighties, however, technology was much more primitive and its power to 
support the thinking and learning process was less understood and appreciated. All we knew about Logo was what we had gleaned from Papert [1] and the work which had been done in Scotland. What we wanted to know was:

- How well could children cope with Logo?

- Given that children need to learn problem solving skills, how effective was Logo in providing them with the necessary tools to allow them to pose problems as well as solve them?

We also were concerned about the amount and nature of teacher intervention. All this was going to involve a good deal of time, watching children. A large proportion of the funding for the project was to pay for this observation. It was hard work getting the proposal accepted because we were looking at some deep and fundamental issues and were not expecting quick returns. One of Her Majesty's Inspectors at the time who was asked to comment on the proposal, replied that it seemed the government was being asked to pay $£ 25000$ for a very expensive report."(Regional Director )

This vision was not perhaps as clearly seen by the staff who worked on the project: "At the first training day, after I had been sat at the computer, he just said to me "Draw a circle". I did it! It was good fun." (Head Teacher); "I remember that I found it very exciting to be in at the beginning." (Logo Teacher); "She <Head Teacher> probably had a clear view, but I don't think in those early days the rest of us did" (Teacher). Nevertheless, they saw the computer very much in terms of what it could do for the learning process: "I hoped that we would be able to use Logo as a method of discussing teaching and learning styles more generally"(Head Teacher); "I enjoyed it because it was so child oriented-children could follow their own questions" (Logo Teacher); "I could see that it was improving their maths"(Teacher).

\section{Early days}

In the early days of IT at JMI this vision began to become a reality.

"Gradually I got the teachers to work in pairs and to share one piece of equipment. This way, they could give each other support because all the versions of Logo we were using had slightly different dialects. They all worked very hard; they took the computers home to practice. I held a meeting for parents and I found that the support I got there was useful. Ideas and expertise grew amongst the children. At one time the significance of 90 degrees was hot news" (Head Teacher).

"On the whole I was very pleased with what we did at primary level. Mostly it was Logo that we concentrated on and even the less able children I thought were reasonable. They seemed to find their way around the keyboard and to be able to handle the computer far better than nowadays" (Teacher). 
"On one occasion I just sat and watched a boy at work. He was about ten and was working with a screen turtle. Now the problem many children have here is to do with left and right. If you are still a bit hazy about directions and you are using a floor turtle, you go and stand behind the turtle, work out what you want to do and then go back to your keyboard and type LEFT or RIGHT which ever it is. With a screen turtle it is much more difficult especially when the turtle is coming down the screen or at an angle so the teacher had helpfully provided a tin of cardboard turtles with $\mathrm{L}$ and $\mathrm{R}$ marked on their front paws. What you had to do was to place a turtle on the screen, orientate it to match the screen turtle and then read off the direction you needed from its paw. This boy was working quietly and efficiently in this way, but I noticed that over the period of twenty minutes I spent watching him, he progressed from placing the turtle properly on the screen, to taking it out of the tin, holding it and just thinking to eventually just putting his fingers in the tin."(Regional Director)

Even so, not all the children had the same attitude: "At the time there was a child who asked what a group of children were getting excited about. When she was told that they were trying to use Logo to draw a circle she asked: "Why go to all that much trouble? Why don't you just put the turtle down and draw round it?" "(Regional Director).

Despite the fact that things had to be introduced slowly the head teacher was pleased with progress: "I believed very much that introducing the staff to Logo as a problem solving tool had to be done in the same way that I was encouraging them to introduce it to their children. There is no point in giving them problems to solve if you insisted on telling them how to do it. I remember overhearing one of the staff saying to a visitor 'We have done it ourselves'. That was very rewarding" (Head Teacher). But she recognized that most of the staff did not see Logo as she did-"but they were keen because they believed that it helped the children with their maths."(Head Teacher)

Towards the end of her time in the school they acquired a four station network which was set up in an activity room with the computers at one end; classes would spend half a day at a time there. Unfortunately she left after 15 months. Although she felt that they had made a good deal of progress, the changes which she hoped to see were not complete. "When she (Head Teacher) left, the deputy head took over temporarily and I was seconded from my teaching responsibility to lead Logo in the school (funded by MEP). I used to work alongside the other teachers and that made a lot of difference. I taught at the school for four years, it was a wonderful time. Computing was new then and it did not matter if you made mistakes-you were working together with the children. Now computing has become established, perhaps it is harder to admit to children when you do not know something."(Logo Teacher) "We 
really muddled along for along time after that (Head Teacher leaving) until we actually began to get a grips with it ourselves."(Teacher)

\section{Maturity}

Gradually the support for the Logo project began to decline: "After leaving to have my first daughter I came back for a period of three months on a part time basis. By then there was a young probationary teacher who had taken over computing, and the Logo work was still progressing. However, although the new head was supportive, she did not give the same lead as (Head Teacher). I think the attitude of the Head makes a great difference."(Logo Teacher)

The present IT coordinator took on the role five years ago because "somebody had to do it ... I was the only one who wasn't afraid of them $<$ computers $>$... in 1976, as part of my humanities degree course I did one unit of computing". Over the following years she gradually improved the provision of IT equipment at the school. They were given a Research Machines PC 186 following a local initiative to get PCs into schools and then with one of the children she won a competition to list the contents of a "time capsule to be opened in 100 years ... so we bought another $<$ computer $>$. The rest have been funded by the Parent Teacher Association (PTA)" (IT Coordinator). By this stage she "started to realize that the 186 was not the state of the art any morecouldn't buy 186's, you are driven by the software packages available, and we needed hard disks, more RAM and a faster processor is nicer" (IT Coordinator). Around about this time a parent helper "installed a network of five IBM PCs (donated by a local Polytechnic)". He has added to this network since, using "bits donated by a local insurance company."(Parent Helper)

The school now has computers in every classroom as well as the PC network and the original network used for Logo (extended to six workstations) in the activity room. It is regarded by parents as being well endowed with computers. However, the early vision about using IT has gone. "The problem is a basic level of understanding-we do not know why we have got computers" (IT Coordinator). "I'm not really certain why $<$ we use IT $>\ldots$ apart from the fact that it's modern technology and it's around and so therefore we ought to use it"(Teacher). The parent helper who installed the PC network, was asked to teach the groups of children who, nine years on, still spend part of their day in the activity room working with Logo using the original network. "It's treated just like cooking <which also takes place in the activity room>."(Parent Helper) He was not given any guidance about what to do with Logo by the teachers (although to be fair he was happy to work without much direction). His view is that for some staff the Logo work is: "just seen as drawing", while others "see it as a means of teaching ideas of space and angle and length". "There's a fair bit of rather dog eared documentation which 
suggests that it must have been used for a more positive maths based teaching in the past" (Parent Helper).

IT is seen very much as a support for the curriculum. "There are members of staff who if they did not have a curriculum document saying you must use IT, they wouldn't" (IT Coordinator). "They use IT because its seen to be a good thing and now its in the National Curriculum, so they've got to do it. They use IT to support various things I take to be in the curriculum, so if you have to write a piece of poetry you can do it on the word processor and you've met two curriculum objectives in one go" (Parent Helper). The main activities are word processing and graphics. The PC network "is only used for word processing so far as I am aware though it does have other software on it" (Parent Helper).

The overwhelming concern seems to be lack of time: "There's so much we have to do each day ... we don't seem to have the time that we used to "(Teacher). "I discussed those sort of things <educational objectives of Logo work $>$ with them and suggested that I could draw up a plan and some worksheets, but they didn't seem to have the time to get involved, though they did seem to think they ought to be interested. Neither the mathematics coordinator nor the IT coordinator seem to have any spare time to develop things that aren't either National Curriculum or keeping the machines going" (Parent Helper). "It's having the time during the day to spend with the children, because of the pressures of other curriculum areas it is very difficult to find time-IT has got low priority basically" (IT Coordinator).

This is coupled with a lack of expertise, "but then if you had the expertise maybe it wouldn't take all the time" (IT Coordinator), and support: "the backup we have had has gone ... we have to buy into a service" (IT Coordinator).

Despite the fact that the computers are seen as "good motivators for children on a one-to-one basis" (IT Coordinator), and the ability of staff to use the computers is improving as they become easier to use, the IT coordinator is pessimistic about the future. "This application <of IT>, the why you use it, I don't think it will get any better. We're all 40 years + and there's no one to teach us" (IT Coordinator).

\section{REFLECTIONS}

What has happened to IT over the years at JMI? It is clear that there is a considerable gap between the vision behind the Logo project and the current use of IT. The idea of using IT (through Logo) to support the teaching of problem solving has not survived. Although Logo is still taught, it is viewed just as an activity with the computers. The focus of IT now is to support the 
curriculum although there is a realization from the staff that they do not really know why they are using IT.

While any successful innovation would have changed with the passage of time, in this case we have more of a cessation than a change, and that is disappointing. In considering why this happened, one of the most significant factors is that the ideas behind the Logo project were never fully adopted by the whole school. For a project to become part of the culture there has to be a transfer of ownership from the project initiators to the organization. This can sometimes be achieved by gradually changing the balance of funding away from the external source, but MEP never seemed to understand this. In the JMI Logo project the head (Head Teacher) was successful at leading and inspiring the staff, but her stay at the school was not long enough for the philosophy of the project (as opposed to its practice) to be sustained. This was not helped by the change in funding arrangement brought about by Local Management of Schools which reduced the support provided by the Local Education Authority. This is certainly a national concern and is highlighted in the latest Government report [2].

Another factor may be the way in which the project was constituted. As a result of the funding arrangements the project looked for success rather than dispassionately sitting back and measuring success or failure. The result was that it highlighted the work of the significant minority for whom the project worked well and glossed over the efforts of those children who were not Logo freaks. Today computers offer so much easily accessible power to children that they have to be single minded problem solvers to be attracted to the Spartan environment which Logo offers.

The extensive changes in education over the last few years have also impacted on JMI and may have contributed to the demise of the Logo project. Before the introduction of the National Curriculum in 1988 teachers were expected to make many decisions themselves. Now they are obliged by law to teach to the National Curriculum and for many teachers this means that they have less scope to follow their own convictions. The teacher involved at the start of the Logo project (Logo Teacher) certainly sees this as a constraint. Sir Ron Dearing is attempting to counter the restrictions of the National Curriculum by bringing back some opportunities for schools to use their own discretion [3], but it is too soon to judge the effects of this at JMI. In addition this will not necessarily ameliorate the other impact of the National Curriculum, highlighted in this case, the consequent lack of time both to reflect and to observe children at work.

It might be thought that the report of "The Three Wise Men" [4] and the Government's interpretation in the "Back to Basics" movement would have restricted the successful adoption of the Logo project. If teachers have to be 
more accountable for their actions, it is more difficult to allow children to follow the wrong track in the belief that they will learn from their mistakes. However, in this case there is no evidence this had any impact.

In conclusion, at the best we might have expected the Logo project to establish at JMI the idea of using IT to support the learning process particularly in the area of problem solving. This did not happen because the early enthusiasm of the head (Head Teacher) and the Logo teacher (Logo Teacher) was not transferred to the majority of the staff. The influence of the subsequent heads was important, but the lack of support from the Local Education Authority and the restriction of time imposed by the National Curriculum were contributory factors. All is not lost, IT is only used passively at the school at present, but there is an awareness that there is more to IT. With a growing familiarity with the National Curriculum teachers may have the time and energy to think about innovation. As the current IT coordinator concluded: "They <computers> haven't fulfilled their potential. Maybe they will in another generation's time."

\section{REFERENCES}

1. Papert, S. (1980) Mindstorms. Harvester Press Ltd.

2. HMSO (1994) The Impact of the IT in Schools Initiative 1990-1993. A report from the Office of Her Majesty's Chief Inspector of Schools.

3. Dearing, R. (1993) The National Curriculum and its Assessment-Final Report. Schools, Curriculum and Assessment Authority.

4. Alexander, R., Rose, R. and Woodhead, C. (1992) Curriculum Organisation and Classroom Practice in Primary Schools. DES. 